\title{
Adolescents' interest experience in daily life in and across family and peer contexts
}

\author{
Esther Slot $^{1}$ (D) Sanne Akkerman ${ }^{1} \cdot$ Theo Wubbels $^{2}$
}

Received: 3 November 2017 /Revised: 22 February 2018 / Accepted: 6 March 2018 /

Published online: 30 March 2018

(C) The Author(s) 2018

\begin{abstract}
This study examined daily experiences of interest in and across the social contexts of family and in- and out-of-school peers. Forty-two Dutch adolescents, aged 13-15 years, provided us with 2 weeks of experience sampling data on their engagement in interesting topics and activities throughout their daily lives. Findings show that adolescent daily life included a diverse range of parallel interests. School-related interests made up a substantial part of adolescents' daily lives, challenging the idea of mere disengagement of secondary school students in academics. Findings also show that some interests are strongly bound to a specific context, while others appear across family and peer contexts. This indicates how multiple contexts can simultaneously feed interests, something that calls for further acrosscontext research of interest development.
\end{abstract}

Keywords Interests $\cdot$ Daily life $\cdot$ Adolescents $\cdot$ Social contexts $\cdot$ Experience sampling method

\section{Introduction}

Adolescence is a developmental phase characterized by many physical, emotional, and social changes (e.g., Crone and Dahl 2012; Steinberg and Morris 2001). During this phase, adolescents develop idiosyncratic interests crucial for the development of self (Krapp 1999, 2002), real-life choices, future

Esther Slot

e.m.slot@iclon.leidenuniv.nl

Sanne Akkerman

s.f.akkerman@iclon.leidenuniv.nl

Theo Wubbels

t.wubbels@uu.nl

1 Graduate School of Teaching, Leiden University, Willem Einthoven Building, Kolffpad 1, 2333

AL Leiden, Netherlands

2 Faculty of Social and Behavioural Sciences, Utrecht University, PO Box 80.140, 3508 TC Utrecht, Netherlands 
orientation, and general well-being (Rounds and Su 2014; Sharp and Coatsworth 2012), and these interests are important determinants for engagement and achievement in school (Ainley 2012; Schiefele et al. 1992). Adolescents tend to seek opportunities to engage with the content of their interests both in and out of school, a process that contributes to their identity formation and, consequently, affects their educational choices (Hofer 2010; Jacobs and Eccles 2000; Krapp 2002).

Pursuing interests in daily life is a complex process, as interests are embedded in and constructed through interaction with social contexts (e.g., Barron 2006; Bergin 2016; Krapp 2002; Renninger and Hidi 2011). Adolescents continually engage in content that may or may not be experienced as interesting, where interest can be seen as a preferred type of engagement (Hofer 2010). On the one hand, situations may steer adolescents toward specific topics and activities for engagement (e.g., Knogler et al. 2015; Tsai et al. 2008); on the other hand, adolescents themselves may also seek opportunities for engagement in particular content (e.g., Hofer 2010; Moeller et al. 2016; Tsai et al. 2008). Most research has investigated these two sources of interest separately.

Whereas interest has been studied extensively in relation to the daily context of school (e.g., mathematics classroom, Mitchell 1993), less is known about interest in out-of-school contexts (Renninger and Hidi 2011). Other research has studied similar phenomena across in- and out-ofschool contexts (e.g., Hedegaard 2014), but how adolescents engage in interests across contexts is particularly unexplored. Only a few scholars have addressed engagement in a particular interest in both in- and out-of-school contexts (e.g., Akkerman and Bakker 2018; Azevedo 2013; Braund and Reiss 2006; Bronkhorst and Akkerman 2016; Uitto et al. 2006). These scholars were guided by an ecological, life-wide approach, meaning they included both in- and out-of-school contexts in their research on learning and development. The purpose of the present study is to begin to fill this gap by studying adolescents' experience of interest across family and peer contexts.

\section{Interests of adolescents}

Interest is a psychological state characterized by an affective component of positive emotion and a cognitive component of concentration (Hidi and Renninger 2006). Interests are always related to particular content (e.g., a material object, topic, activity, or idea; Renninger and Hidi 2016, p. 16). It can be triggered through adolescents' explorations and social interactions with family, teachers, and peers. This interest can be momentary, but it might also develop into a more enduring person-object relation (Krapp and Prenzel 2011). Whether interest persists over time is dependent on the person's needs and goals, other (competing) interests, and the opportunities and demands in his or her environment (Eccles et al. 1993; Hofer 2010; Jacobs and Eccles 2000).

Whereas most researchers have focused on either momentary or longer-term interests, this study includes both by assessing the everyday experience of interests in adolescence (Tsai et al. 2008). This is important given the worldwide concern on the developmental decline of adolescents' academic interest (Hidi and Harackiewicz 2000; Potvin and Hasni 2014). Although previous research on academic interests has often reported on the energizing effects of interest on learning, the field struggles in finding a full explanation for this phenomenon (Renninger and Hidi 2011). We therefore deem it important to study the experience of interest beyond the academic domain, also taking into account out-of-school topics and activities that adolescents experience as interesting in their daily lives (with peers, family). Indeed, research on adolescents' daily lives suggests that most interests tend to evolve naturally from (active) leisure activities (e.g., sports, hobbies), presumably because these activities trigger both 
intrinsic motivation and deep attention and thereby support adolescents in discovering their personal interests and talents (Larson 2000; Sharp and Coatsworth 2012; Csikszentmihaly and Larson 2014; Kleiber et al. 2014).

Besides leisure activities, socializing is mentioned as an important source of interest in adolescence, as it triggers feelings of intense engagement and belonging (e.g., Coatsworth et al. 2005). Also, consumptive and interactive media such as TV, video games, computers, and smartphones play an increasingly large part in the daily lives of the current "Internet generation" (Bassi and Della Fave 2004; Van den Beemt et al. 2010). Maintenance interests (e.g., dressing, styling, personal care, transportation) are (an often necessary) part of life but might still prompt interest (Hofer 2010). Finally, although scholars report a general lack of interest in productive activities such as school (Hidi and Harackiewicz 2000), this may vary per school subject (Bergin 2016).

Summing up, empirical results to date lack a comprehensive view on adolescents' experience of interests in daily life. Following the research stated above, we aim to investigate all interests that adolescents encounter in daily life, including interests in domains of leisure, school, maintenance, socializing, and media, thereby focusing on adolescents aged 1315 years, a period in life in which interests are already found to be relatively stable (Low and Rounds 2007).

\section{Contexts for adolescents' interest experience}

Daily life in adolescence is typically built up out of multiple contexts (Phelan et al. 1991). Every context includes a relatively stable structure of social relationships and meaning, imposing its own rules and expectations on the individual, thereby creating opportunities or constraints for interest engagement in particular content (Akkerman and Bakker 2011; Zittoun and Gillespie 2015). Research on adolescents' ecological systems and time use has made an empirical distinction among the social contexts of family (parents, siblings, extended family), peers in school (e.g., classmates), and peers out of school (e.g., friends, romantic relationships) (Anderson 2013; Bronfenbrenner and Morris 1998; Smetana et al. 2006). These contexts tend to be different on epistemic, social, and cultural levels, hence also in the extent to which specific interests might be experienced or facilitated (Bronkhorst and Akkerman 2016; Grossen et al. 2012; Phelan et al. 1991).

Studies that have explored interest across different contexts suggest parents to be the most important facilitators of experiencing and developing interest, as they provide their children with opportunities and resources needed to engage in particular interests (e.g., paying for piano lessons, buying clothes, going to a museum) (Bergin 2016; Crowley et al. 2015; Levey 2010). By co-constructing knowledge with their child about a specific topic through dialogue and activities, parents can help their children build the so-called islands of expertise already at a young age (Crowley and Jacobs 2002). In adolescence, parental involvement continues through the mental support of their children, for example, in supporting their interest in technology (see Barron 2006). Sibling relationships can also become more supportive with age, although this has not been researched in relation to interest (Smetana et al. 2006). Friends or peers in or outside of school can positively or negatively influence interest in academic topics, achievement, and career selection (Bergin 2016). This might occur through socialization and selection processes; adolescents try to fit their interests to their friends' interests and choose friends who have similar interests (e.g., Low et al. 2005). In sum, the literature shows 
that family and peers in and out of school might all support interests in daily life, but whether and how interests are simultaneously displayed in these social contexts is particularly unexplored.

\section{Across-context perspective}

The described interplay between interests and multiple contexts in daily life requires an "across-context" perspective (Akkerman and Bakker 2018; Bronkhorst an Akkerman 2016; Falk et al. 2016). Such a perspective tries to expand the common unit of analysis, that is, a single context (e.g., Valsiner and van der Veer 2000), and allows for a study of the adolescent's interests in continuous interaction with different social contexts over time (i.e., idiosyncrasy) (Azevedo 2013; Barron 2010; Bergin 2016; Pressick-Kilborn et al. 2005). Such a holistic approach is in line with recent developments in the field of educational and learning sciences, where researchers have started to investigate how different social contexts simultaneously promote or constrain learning and development in daily life (Falk et al. 2016; Hviid 2016; Torquati and Rafaelli 2004). This approach calls for new methodologies that allow for the investigation of everyday (inter)actions. Therefore, our study will use an experience sampling method (ESM), providing us with an archive of highly ecologically valid data (Hektner et al. 2007).

An across-context perspective enables us to explore the extent to which different interests appear in different contexts, examining how the family, school peer, and out-of-school peer contexts generate experiences of interest. Research on this topic is still in its infancy, but preliminary evidence suggests that adolescents may (intentionally) strive for continuity in their lives both in and over time, trying to pursue parallel interests (Akkerman and Bakker 2018; Barron 2010; Bronkhorst and Akkerman 2016). First, interests initially triggered in one context can be pursued and/or further developed in another context later on in time (Barron 2006; Crowley and Jacobs 2002). For example, an interest in modern art that is sparked in a museum perhaps develops further at school by doing an assignment on modern art. Hence, an interest can be continued across contexts over time. A second scenario might be at hand when differences between social contexts are temporarily united in one interest-related event (Phelan et al. 1991; Hviid 2016), for example, when a child visits a museum of modern art with both his parents and friends from school (i.e., across-context continuity in time). On the other hand, interests can also be situated in a specific context, in that they are specifically bound to the physical, social, and material resources and opportunities within a particular context (we call this across-context discontinuity) (e.g., Akkerman and Bakker 2018; PressickKilborn et al. 2005). This observed distinction between continuity and discontinuity requires an exploration of the extent to which interests appear in or across contexts in daily life.

\section{Research questions}

Two research questions are posed:

1. In what domains do adolescents report to experience interest in their daily lives together with family, peers in school, and peers out of school?

2. To what extent are adolescents' interests continuous across the contexts of family and in- and out-of-school peers, and does this continuity differentiate for domains of interest? 


\section{Method}

\section{Participants}

All ninth graders from four Dutch secondary schools were invited to participate in the study. Since our aim was to study a sample of 50 adolescents, we used stratified sampling based on school class and gender to select the sample that would take part in our study $(n=90)$, anticipating for possible attrition rates. All students were from the higher secondary educational levels (i.e., senior general secondary education and university preparatory education), as we did not approach any students from the (lower) vocational education level. Adolescents took part in our study voluntarily. Informed consent was obtained from all individual participants and their parents before participation.

Participants were offered financial compensation if they fulfilled certain payment criteria $(25 €)$. These criteria were as follows: (1) adolescents should fill out at least three reports a day, (2) spread throughout the day (i.e., morning, afternoon, and evening), (3) their assessments should be accompanied by clear and elaborative comments on their experiences, and (4) they should at least have added ten contacts and two different social groups to their mobile application. Students who did not meet these criteria were excluded from the study $(50 \%$, $n=45$ ). Three participants (3.3\% of 90) did not complete the data collection due to technical problems with their smartphone. Hence, the final sample consisted of 42 adolescents ( 29 girls and 13 boys) who met all criteria and finished the data collection period. Ethical approval for this study was received from the ethical review board of the Faculty of Social and Behavioural Sciences of Utrecht University.

\section{Procedures and measures}

\section{Smartphone application “inTin”}

We used ESM to study interest experience in and across contexts in daily life. This is a valid and reliable self-report measure that can be used to obtain empirical data on psychological states, daily activities, and social interactions (Csikszentmihaly and Larson 2014, p. 35). ESM entails that participants are studied in their natural environments and that experiences are measured in a systematic and momentary way. Widely accessible smartphones offered opportunities to apply ESM on our sample. The smartphone application that we used is called "inTin" (i.e., interested in) and was developed by Akkerman and Bakker (2012-2014) for studying the development of multiple interests in all life domains and in interaction with the social network of its users. It was piloted and validated in 2015-2016 and has proven to be a reliable and valid instrument to study the idiosyncratic nature of interests in daily life, depending on proper instruction and completeness of the social network that participants add to the application (Akkerman and Bakker 2012-2014).

\section{Assessment procedure}

Participants were beeped on their smartphone every $2 \mathrm{~h}$ during waking hours to report their momentary experiences for two consecutive weeks in February 2016, with a maximum of eight per day. A few months prior to the data collection, they received a 1.5-h instructional briefing, during which they discussed what interests are and how to 
use the application. Additionally, they practiced filling in the application and were encouraged to ask questions. After the instructional meeting, participants were asked to take part in a pilot study in order to be prepared for the daily task of reporting interest activities repetitively.

At the start of the actual data collection in February, participants had to enter all topics and activities that they perceived as interests. This resulted in a list of interests at the start for each participant. Similarly, at the start, participants were asked to list all social contacts that are important to them or that they see often (Fisher and Shogren 2016). They were asked to designate the type of contact by choosing one or more options from a list including the options of classmate, friend, family, teacher, acquaintance, neighbor, colleague, or other. They were also required to add at least two social groups (i.e., cluster of social contacts), for example, "class" or "family." Participants were free in choosing the composition and name of a group. Individual contacts could be added to one or multiple social groups; for example, John can be part of both the group "class" and the group "hockey team." During data collection, the resulting lists could be extended, as participants had the possibility to add interests, contacts, and groups on every reporting occasion.

Participants received triggers with a 2-h interval during each day for 14 days. They received the first trigger $2 \mathrm{~h}$ after their reported wake-up time and the last trigger at maximum half an hour before their reported bed time. After each trigger, participants could report on the interests they just spent time on. If so, they reported for each interest with whom and how (e.g., face to face, phone, Internet) they were involved in the interest. This creates a so-called interest-contact event for every reported interest. Thus, a moment in time where an object of interest coincides with one or more contacts from a participant's social network. When reporting "with whom," adolescents could select "alone," "an individual contact," or "a social group" using the contact/network list they created. At the end of each interest-contact event, they were asked to answer two open questions: "What did you do/think/talk about?" and "What did you think was interesting about this event?" There was no restriction as to how fast adolescents had to respond to their trigger, since this might increase the intrusiveness of the method further. After a response, a new trigger would follow after $2 \mathrm{~h}$. During data collection, every participant was supported and motivated by a research assistant. These assistants acted as coaches, instructed to create a sphere of positive encouragement ("Good job, you are almost halfway!") and helped participants to fulfill the criteria of payment ("Do not forget to report your interests this morning/afternoon/evening: Did you spend time on any interesting topics or activities?").

\section{Data analyses}

All data provided by participants were directly saved on an online users database with secured access for the first and second authors set up and maintained by a professional web team of Utrecht University.

Interests In total, the 42 participants reported 726 interests. Due to a high similarity of some of the interests (e.g., watching the news or watching today's bulletin), two or more interests were merged into one in several cases (e.g., watching the news), resulting in 705 interests that were coded. Of the interests added to inTin at the start of the data collection, $4.8 \%$ were not reported in any interest events during the 2 weeks of data collection and were therefore not included in the analyses, resulting in 671 interests. 
Based on Kleiber et al. (2014), a coding scheme was developed to code all interests. We adopted their distinction among leisure, productive, and maintenance activities. We also included the specific domain "media," since media play an increasingly large role in the socialization and learning of adolescents (Barron 2006; Bassi and Della Fave 2004). Additionally, unlike Kleiber et al. (2014), we regarded interests in social topics and activities as a separate domain ("socializing"; Azevedo 2011). Finally, we added the category "other" in order to code the interests that could not be attributed to any other domain.

The Appendix includes the final coding scheme with six domains of interests, each subdivided into detailed codes. The domain productive includes interests related to school, i.e., academic (math, English, science, history) and nonacademic classes (e.g., arts, music, PE), homework activities, and other interests related to school, such as career events. Leisure interests included interests in structured or unstructured leisure, where structured leisure refers to interests in institutional or organized sports and hobbies, and unstructured leisure interests refer to, for example, reading, arts, travel, and unstructured sports such as running or fitness. The domain socializing includes interests in social interaction (chatting), hanging out with friends, going out, partying, and shopping. Media interests are both interests in consuming media (reading the news, watching TV) and interacting with media (gaming, social media). The maintenance domain refers to interests concerning self-care and directly serving well-being, such as doing your makeup and going to the hairdresser (see Kleiber et al. 2014). Interests in the category other are interests that could not be attributed to one of the other domains. This might concern interests related to a specific topic, weekend jobs, designing, repairing PCs, thinking/self-actualization, or miscellaneous interests such as "I want to sleep."

As was recommended by Akkerman and Bakker (2012-2014), a code was always based on the label provided by the participant and the comments in the interest-event data (what did the adolescent do/think about/talk about and why did he/she find this interesting?). Participants were sometimes more specific about the content of their interest in their comments than in the label they had used in reporting their interest. An interest in watching TV could mean that one is really into watching TV, which means that this interest would be attributed to the media domain, or perhaps watching TV was part of their homework, which would make it a schoolrelated interest. The coding scheme for interests was tested on a randomly selected subset of data and independently blind coded by another researcher. This led to minor changes in the coding scheme due to different interpretations of some of the detailed codes. The interrater reliability was calculated after having a third researcher double code 100 randomly selected interests (approximately 14\% of the total), with an acceptable result of ICC $=0.79$ (Cicchetti 1994).

Contacts Together, the 42 participants in this sample added 1195 unique contacts. When adding contacts, participants were able to select more than one type of relation. Almost all contacts could be attributed to one of the three social contexts (family, school peers, or out-ofschool peers) based on the relation type and the social groups they belonged to (e.g., sport team, school class, church group, peer group). A very small part of the contacts were teachers, adult neighbors, or pets, which were excluded from further analyses as they could not be attributed to one of the contexts in focus $(2.9 \%, 35$ contacts). Furthermore, in 315 cases (26.4\%), individual contacts received a double relation-type code, mostly (241 times) including the simultaneous relation of classmate and friend. These contacts were attributed to the school context, except when they belonged to both an in- and out-of-school social group (i.e., 
multimembership). This was determined through interpretation of the label that was attributed to the social group (e.g., "hockey team" refers to an out-of-school group). In total, 14 contacts were attributed to both the school and out-of-school contexts, five contacts were both family member and belonged to the out-of-school peer context, and one contact was part of both the family and school peer contexts.

Three types of across-context continuity In order to determine the across-context continuity of interests, we first made a distinction between private and socially shared interests, where private interests are exclusively pursued alone. For the interests shared with significant others, we distinguished between interests that were shared with only one context in and over time (discontinuity), or across contexts in and over time (continuity).

For across-context continuity, we initially defined two types: the first regarding interests that were shared with significant others across events (i.e., over time), and another describing interests that were shared with significant others within an event (i.e., in time). Type 1 is most easy to interpret, as it regards interests that were shared across contexts and events (e.g., Pete plays soccer twice during the wave, first with his father and then with his classmates). However, for type 2, i.e., continuity found within an event, we had to differentiate between two equivalent but conceptually different subtypes. The first subtype (2a) refers to a situation in which two contexts are united in one interest-contact event (e.g., Pete plays soccer with his father and classmates simultaneously). The second subtype (2b) is needed in order to identify multimembership. Across-context continuity can also exist solely due to a significant other representing two contexts in one interest-contact event (e.g., Pete plays soccer with his twin brother Dave, who is also his classmate). Hence, we eventually identified three types of across-context continuity that we will report on in the "Results" section. Please read the illustrative examples in the "Results" section for further elaboration on these types of across-context continuity.

Interests nested in persons Since interests are nested within persons, it was necessary to perform a check on whether we were allowed to analyze (dis)continuity at the interest level, i.e., if interests from the same person were not more alike than interests from different persons. We conducted an intercept-only model in HLM7 Student Version (Raudenbush et al. 2011) with the mean-centered outcome variable "continuity" (uncentered $M_{\text {continuity }}=0.07$ ) and calculated the amount of variance explained at level 1 (interests) and level 2 (person level). Only $11.12 \%$ of the differences in continuity were attributed to the person level, although the chi-square was significant (ICC $=0.11$, $\left.\chi^{2}[42]=119.94 ; p<0.001\right)$. For the scope of this article, we decided to focus on the interest level in explaining continuity across contexts.

\section{Results}

\section{Descriptive statistics}

Adolescents completed 2642 assessments in 14 days, which equals an average of 62.91 assessments per participant (range is 48-95). On average, adolescents experienced at least one interesting topic or activity in three out of four assessments. 


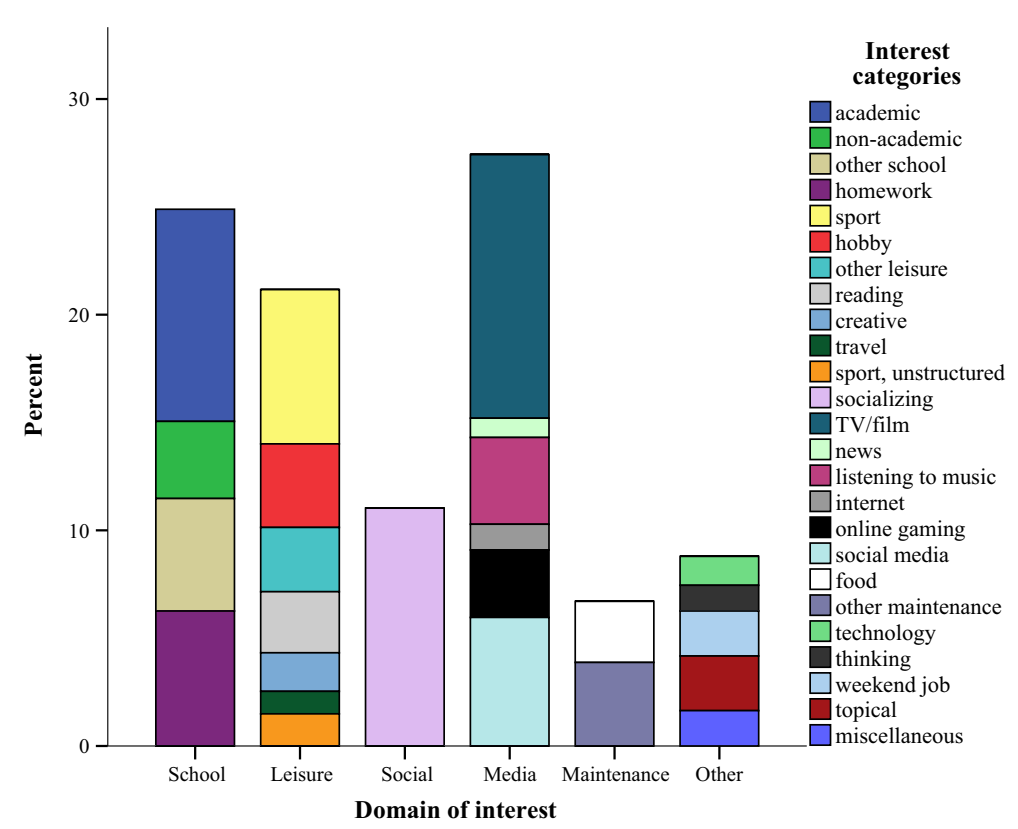

Fig. 1 Percentages of interests reported in six different domains, stacked per interest category

In total, 671 unique interests were reported (see Fig. 1). The domain most frequently reported was media, with $27.4 \%$ of the interests, such as watching TV/film, listening to music, social media, news, Internet, and online gaming. Watching TV/film was the most frequently reported category, representing $44.6 \%$ of the media-related interests. School also appeared to be a substantial source of interest; $24.9 \%$ of the reported interests were attributed to that domain. Academic school interests were reported most frequently (approximately $40 \%$ of all school-related interests), such as interests in (topics related to) languages, biology, math, science, chemistry, or history. Leisure interests accounted for $21.2 \%$ of the total, with structured hobby or sport interests as the largest category, including those in a more formal, institutional setting, such as playing the piano, drumming in a band, and playing basketball or hockey. Socializing interests represented more than $12 \%$, and the domains of maintenance and other captured 6.7 and $8.8 \%$ of the interests reported, respectively.

The largest proportion of contacts added to the application was attributed to the school peer context $(41.1 \%)$, followed by the out-of-school peer and family contexts (29.7 and $29.2 \%$, respectively). We found that $33.8 \%$ of the interests were experienced in private, i.e., engagement in objects of interest without the presence of significant others. The other $66.2 \%$ of interests $(n=444)$ were shared with one or more significant other(s) in at least one reported event. The following section further explains which domains of interest were associated with what social contexts (i.e., interest-context ties).

\section{Interest-context ties}

Figure 2 shows the different domains of interests that appeared in the family, school peer, and out-of-school peer contexts. In total, 1119 interest-context ties were found across 962 reported events. On average, this means that an event was associated with 1.16 contexts. Findings show 


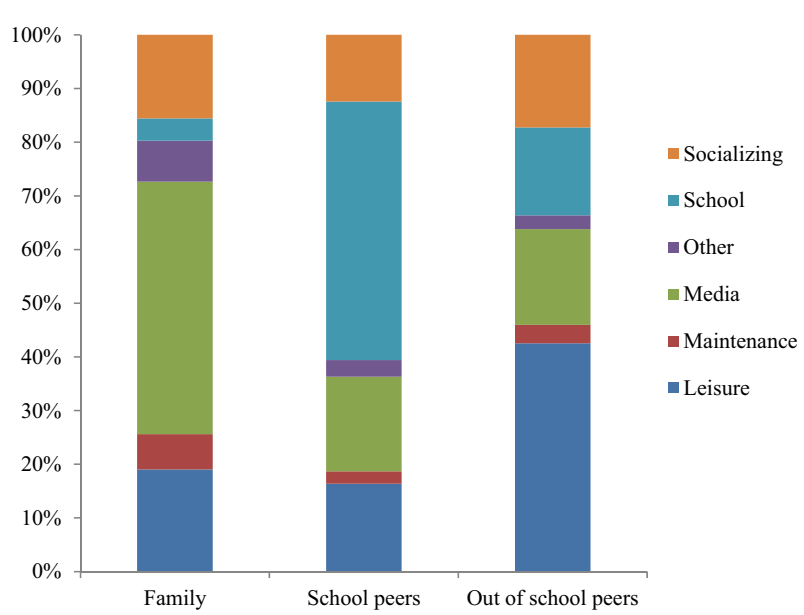

Fig. 2 Percentages of interest-context ties $(n=1119)$ reported per social context over all domains of interest (socializing, school, other, media, maintenance, and leisure)

that all three contexts were associated with a wide range of interests, although some differences became apparent. Family was associated most frequently with interests in media (47.1\%), especially watching TV/films. Interests in leisure (mostly sports and hobbies) and socializing were also often associated with family (19.0 and 15.6\%, respectively). School peers were most often reported in relation to school-related interests (48.1\%), such as academic classes. Out-ofschool peers appeared to be associated with leisure interests the most (36.77\%), particularly sport-related interests. Also, like family, they were associated with interests in media and socializing (17.8 and $17.24 \%$, respectively). These findings show that some interests appear more often in some social contexts than others. At the same time, every context was associated with all domains of interest, leading to the question in our next section of to what extent interests are engaged in across contexts.

\section{Across-context continuity}

Concentrating on the interests that were socially shared $(n=444)$, a large part $(74.5 \%, n=331)$ was discontinuous, i.e., engagement with that specific topic or activity was situated in only one context. Of these discontinuous interests, $33.2 \%$ were situated in the family context, $45.9 \%$ in the school peer context, and the remaining $20.9 \%$ were related to the out-of-school peer context. Still, one in four of the socially shared interests $(n=113,25.4 \%)$ was continuous across contexts. Figure 3 demonstrates how the different domains of interest were distributed across the three types of across-context continuity. In general, the figure shows that most domains of interest appeared across all continuity types. More than half of the interests that appeared across contexts also appeared across events, i.e., over time (type 1, 51.3\%). This across-context continuity applied mostly to media interests. Over a third of the interests $(34.5 \%)$ was continuous across contexts due to multimembership of an actor involved (type $2 \mathrm{~b}$ ), with school and leisure interests as the biggest domains. Interestingly, only $2 \%$ of the actors in the networks of our participants were responsible for this proportion of across-context continuity. Finally, the remaining interests $(14.2 \%)$ were continuous across contexts within an event (type $2 \mathrm{a}$ ), which mostly concerned socializing interests. Together, leisure, school, and media interests accounted for almost $75 \%$ of the continuous interests, whereas maintenance 


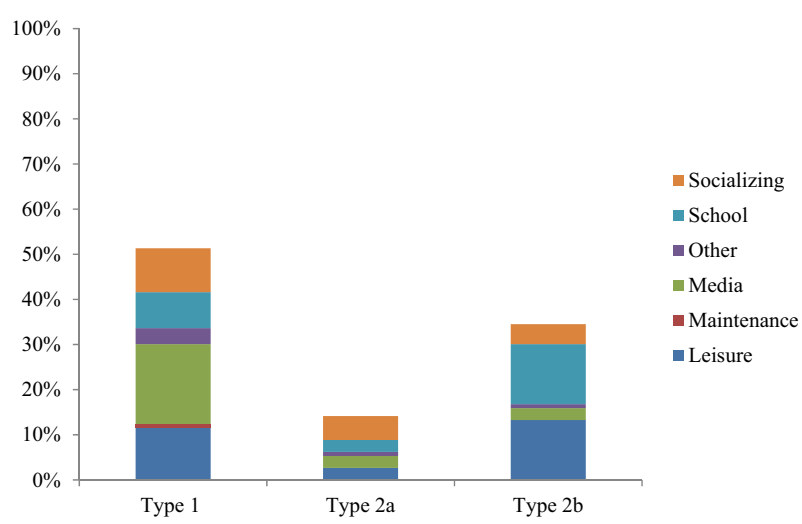

Fig. 3 Percentages of all domains of interest represented in the three types of across-context continuity, where type 1 refers to continuity over time and types $2 \mathrm{a}$ and $\mathrm{b}$ in time

interests were hardly represented (i.e., only one interest in maintenance was shared across contexts).

In order to further unravel the continuity across the contexts of daily life, Fig. 4 reveals the extent of continuity across contexts. Across-context continuity was apparent among all contexts, with only five interests found to be continuous across all three contexts. Most continuous interests were found between school peers and out-of-school peers $(n=54)$, followed by family and school peers $(n=31)$ and then family and out-of-school peers $(n=$ 23). It is noteworthy that the across-context continuity patterns resulted from interests of a wide range of participants. For example, the interests that appeared across school and out-ofschool contexts were reported by 19 participants. It should also be noted that the strong connection between the contexts of school peers and out-of-school peers was caused by multimembership: $65 \%$ of the interests in both of these contexts were continuous in time due to a significant other simultaneously attributed to both the school and out-of-school contexts.

\section{Illustrative examples}

In order to clarify how the three types of across-context continuity might be expressed at the interest level, three examples were selected based on the domain of interest most frequently

Fig. 4 Number of discontinuous interests (in circles, $n=331$ ) and continuous interests among the social contexts of family, school peers, and out-of-school peers $(n=$ 113)

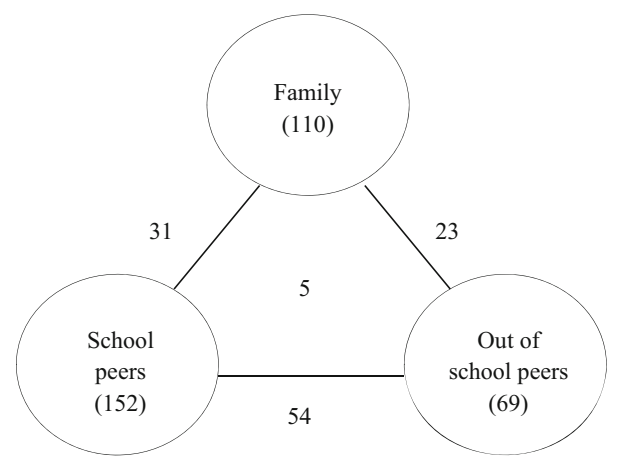


observed within a specific type of continuity. For the sake of diversity, we chose exemplary interests from three different participants in three different schools.

Type 1: across-context continuity over time Figure 5a shows the engagement in an object of interest of one of our participants, Sergio. Over $30 \%$ of the interests continuous across contexts and events (i.e., over time) were related to media, for example, (online) gaming. Sergio is interested in playing different (online) games, for example, Minecraft. He reported to play these games with significant others at six events $\left(\mathrm{T}_{n}\right.$ in the figure) during the 2 weeks of data collection. At $\mathrm{T}_{1}, \mathrm{~T}_{3}$, and $\mathrm{T}_{5}$, he reported to play games with his sister, Lara. At $\mathrm{T}_{4}$, he discussed his new PlayStation set with two of his out-of-school friends, Nick and Bryan. At $\mathrm{T}_{2}$, he talked about one of the games he liked to play, The Last of Us, with his classmate and friend Luciano. Finally, at $T_{6}$, he played the pocket edition of Minecraft with one of his friends from out of school, Joelle. Hence, Sergio shared gaming with all three contexts over time in different manners, i.e., as an activity in itself but also as a topic for discussion.

Type 2a: across-context continuity in time Figure $5 \mathrm{~b}$ shows the engagement in an object of interest of another participant, Nora. Socializing made up more than $30 \%$ of the interests that were continuous across contexts and within events (i.e., in time). She reported that she went to the movies with her girlfriend clique, labeled by her as the "Chicks." Some of these friends were attributed to the context of school, as they were in her class, and others to the outof-school context. Thus, the two contexts were temporarily united in one interest-contact event, i.e., when they went to the movies together.

Type 2b: continuity due to multimembership In Fig. 5c, we depict an illustrative example from the domain of school. For this type of continuity, we chose to exemplify the interest "physical exercise" (PE) from our participant Ariel. She reported to have been engaged in her PE class twice during the data collection period, both times together with one of her social groups labeled by her as "school." The across-context continuity resulted from a significant other named Larissa, a girl who is in her class, dance institution, and whom she also gets to meet in church. Because Larissa represented both the school peer and out-ofschool peer contexts, this school-related interest was attributed to type $2 \mathrm{~b}$ continuity.

\section{Discussion}

Interests of adolescents have attracted growing attention as a vehicle to promote development of self and engagement and achievement in school (Ainley 2012; Krapp 2002; Rounds and Su 2014; Schiefele et al. 1992; Sharp and Coatsworth 2012). Interests, however, cannot be easily studied as they are embedded in and constructed through interactions in everyday life. This study was the first to assess interests with an ESM. The adolescents in our sample (aged 1315 years) were beeped up to eight times a day for 2 weeks, asking them to report the interests that they just spent time on as well as the significant others that they shared the event with. Using a mobile application to assess their life-wide interests has provided us with a much more detailed representation of adolescents' everyday experience of interests than previous research so far has revealed. 
a

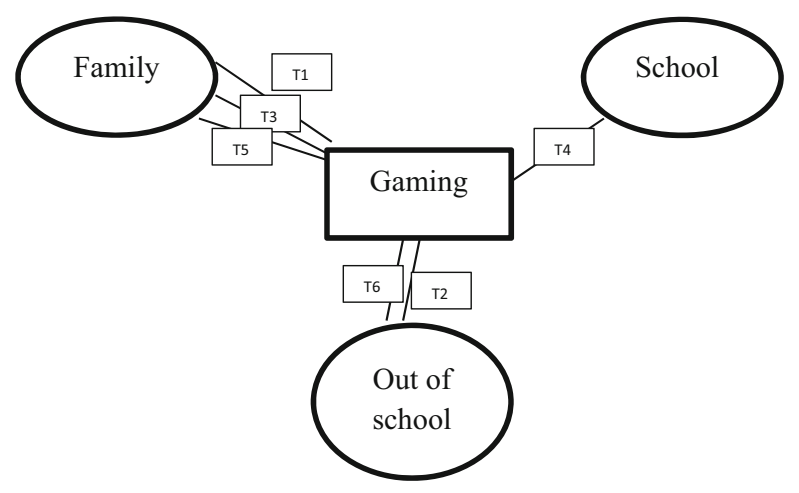

b

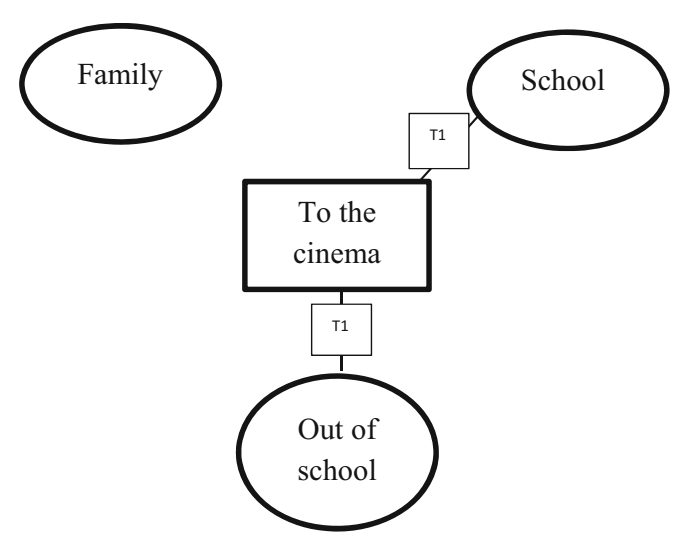

C

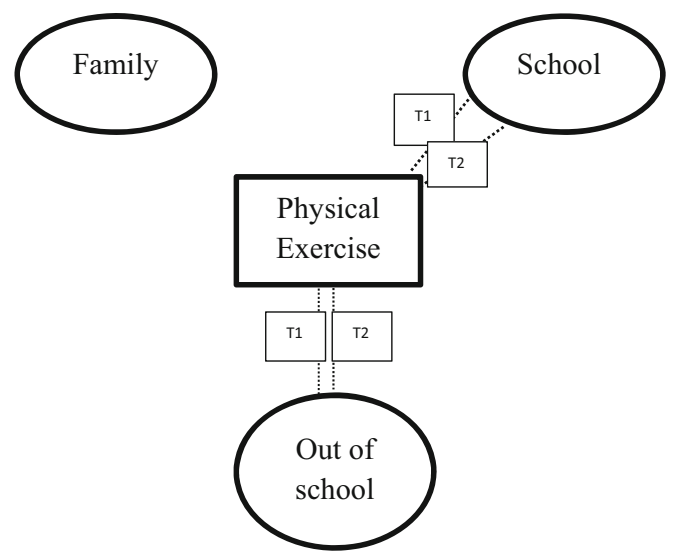

Fig. 5 a Example of continuity across events (i.e., over time), in which every $\mathrm{T}_{n}$ represents an interest-context tie, and a different $n$ refers to a different event (i.e., point in time). $\mathrm{T}_{1}$ refers to the first interest event in the week in which Sergio reported gaming and $\mathrm{T}_{6}$ the last. $\mathbf{b}$ Example of continuity within events (i.e., in time), in which $\mathrm{T}_{1}$ refers to the interest-context tie between the interest "to the cinema" and the contexts of school peers and outof-school peers, as these were temporarily united in one event. c Example of continuity within events (i.e., in time) due to multimembership, in which every $\mathrm{T}_{n}$ represents an interest-context tie, and a different $n$ refers to a different event (i.e., point in time). The presence of the dashed lines indicates that multimembership caused the continuity across contexts 
Regarding the first research question, our findings indicate that adolescents engage in a wide range of interests throughout their daily lives, both in and across the social contexts of family and inand out-of-school peers. More specifically, we showed how adolescents' interests in school-related topics and activities make up a substantial part of their daily life, challenging the idea of mere disengagement of secondary school students in academics (Hidi and Harackiewicz 2000; Potvin and Hasni 2014). This result may encourage other researchers to use ESM to get a more detailed grasp on the experience of interests in and beyond the school walls. Secondly, in line with our expectations, adolescents also engaged in leisure interests (e.g., sports and hobbies) regularly. Indeed, these activities are believed to have great potential to be experienced as interesting, as they are often novel, challenging, and can meet adolescents' need for well-being and belonging, thereby triggering an experience of flow (Hofer 2010; Kleiber et al. 2014; Larson 2000).

Importantly, our research has shown that many "ordinary" aspects of daily life can actually trigger interest in adolescents, instead of being merely a "routine" activity (Larson and Verma 1999). Watching television, eating, and gaming are examples of activities that were experienced as functional. Perhaps, such "routine-like" or "time-filler" activities were experienced as interesting because adolescents can share them with their significant others, or because they can relax and relieve stress while zapping or playing a game. Future research should try to gain more in-depth knowledge on why adolescents experience particular content or activities as interesting, as to unravel the origin of interests as a product of everyday (inter)action.

\section{Context-(in)dependency of interests}

Regarding the second research question, we can conclude that interests are to some extent experienced across social contexts in adolescent's daily lives (i.e., across-context continuity). This finding fits with Barron's (2010) suggestion that adolescents strive for some continuity in the interest topics and activities that they experience throughout the different contexts in which they participate. Comparing domains of adolescents' interests, we found that adolescents tended to experience media interests (e.g., gaming, social media, TV/film, music) most often with significant others from different social contexts (e.g., family and school peers). Again, this is in line with the research of Barron $(2006,2010)$ describing how these "technologydriven" interests can transgress initial contexts or spaces, as material and relational resources are likely to be available across different contexts.

However, our findings also showed that other interests were strongly context-dependent (i.e., across-context discontinuity), illustrating that interests can also be bound by the materials, opportunities, and resources of a specific context (e.g., Pressick-Kilborn et al. 2005). Hofer (2010) referred to this context dependency as the "opportunity structure" it provides for a certain interest. For example, maintenance interests (e.g., doing makeup) showed a high level of context dependency because these types of interests strongly rely on a daily routine-like structure (e.g., Krapp 2002). On the other hand, interests in media might demarcate a more hybrid structure, as adolescents are provided with ample opportunities to engage in them across contexts (Gutiérrez et al. 1999). To fully comprehend the contextualized nature of interest, we recommend future research to study the situational engagement of an interest of a specific individual in more detail. An example of such a study has been done by Azevedo, who studied the complex configuration around a single interest, which he refers to as the "line of practice" (Azevedo 2011). Understanding how interests originate and develop in interaction with various social, material, and cognitive resources, both in and across contexts, is crucial in order to be able to foster long-term interest, not only in but also outside the school (Bergin 2016). 
An unexpected finding that we would like to discuss here is that interests in the domains of school and leisure were often found to be continuous across contexts due to multimembership of a significant other involved (e.g., a person is both a classmate and a teammate). Multimembership was a direct result of our choice to extend the unit of analysis from a single context to multiple contexts and demonstrates how contexts can overlap (i.e., in terms of social others that belong to two or more worlds). People who (un)intentionally function as a bridge between social contexts may be seen as brokers (e.g., Wenger 2010). Brokers form a unique link between otherwise separated contexts (Akkerman and Bakker 2011; Bronkhorst and Akkerman 2016); hence, these people can play an important role in establishing continuity. Interestingly, only a dozen significant others functioned as brokers ( $2 \%$ of the total), impacting over $30 \%$ of the continuous interests. Most brokers were positioned between the school peer (e.g., class) and out-of-school peer contexts (e.g., sport club, church). Multimembership is an important issue to take into account in any research taking an across-context perspective.

\section{Limitations and future research}

Although the present study contributes to the research on interests in daily life, the findings should be interpreted in the light of some limitations. First of all, the adolescents in our sample were all in the higher educational levels in the Netherlands and presumably grew up in families with more opportunities, socially and materially, than students in the vocational levels. This might have affected the interests that they reported and it would be interesting to see the differences with lower social and more ethnically diverse groups.

Secondly, in order to achieve an ecologically valid sample, we selected a subsample of adolescents for the purpose of this study, which might include adolescents with a higher interest level and more and broader interests in general than the adolescents who did not fulfill the criteria for selection. Also, the novelty of assessing interest through ESM required us to place a large emphasis on describing the interests and contexts that adolescents reported, which can be regarded as only a first step toward a more thorough understanding of interest development over time, in and across social contexts in daily life. Time-series analyses or dynamic multilevel modeling may serve the purpose of investigating intensive longitudinal interest data in a more quantitative manner (Hamaker and Wichers 2017). Such techniques would enable a paradigm shift toward a more person-centered perspective, acknowledging both within-person dynamics and between-person differences at the same time.

Despite these limitations, our study was the first to use ESM to measure the experience of interests in daily life among adolescents. Future research can build on our work by further exploring possibilities for analysis with moment-to-moment interest data, such as with regard to the development of interests over time and how this development might be different for interests that are highly context-dependent than for interests that show a more hybrid structure (e.g., media interests). Another interesting focus might be to investigate the development of content, e.g., how a topic-specific interest might develop over time into a strongly internalized interest, supported by a diverse range of topics and activities (see Akkerman and Bakker 2018; Zittoun 2015). Furthermore, a person-centered approach is needed to study adolescents' rationale for pursuing interests in or across contexts. Previous research has argued that some adolescents (un)consciously try to establish continuity across contexts, whereas others might keep their contexts "separated" (e.g., home and school, Phelan et al. 1991).

Taken together, the study described here was the first empirical study to take a holistic approach on adolescent's everyday experiences of interest, using ESM to assess a life-wide range 
of interests experienced in and across family and peer contexts. Our findings illustrated how adolescent daily life can include a diverse range of (parallel developing) interests, some of which are context-dependent and others that appear across contexts. This demonstrates the importance of adapting an across-context perspective in order to understand how different social contexts simultaneously promote youth development.

\section{Appendix}

Table 1 Coding scheme for reported interests

\begin{tabular}{|c|c|}
\hline Domain of interest & Description \\
\hline \multicolumn{2}{|l|}{ Productive } \\
\hline Academic school & $\begin{array}{l}\text { Academic classes, projects, and tasks, such as Dutch, English, math, science, } \\
\text { history, geography }\end{array}$ \\
\hline Nonacademic school & Nonacademic classes, projects, or tasks, such as art, music, PE \\
\hline Other school & Breaks or other activities not related to class (e.g., profile choice) \\
\hline Homework & Homework activities \\
\hline \multicolumn{2}{|l|}{ Leisure } \\
\hline Structured leisure & Institutional or otherwise organized (including trainings, gatherings) \\
\hline Sport & $\begin{array}{l}\text { Playing sport, providing trainings, or other activities to do with sports inside an } \\
\text { organizational structure }\end{array}$ \\
\hline Hobby & $\begin{array}{l}\text { Structured hobbies, such as piano playing (including the lessons), or youth } \\
\text { clubs }\end{array}$ \\
\hline Unstructured leisure & $\begin{array}{l}\text { Outside institutions, absence of an organizational structure, and/or incidental } \\
\text { leisure activities or topics }\end{array}$ \\
\hline \multicolumn{2}{|r|}{ When } \\
\hline Creative & Drawing, photography \\
\hline Travel & Holiday, traveling \\
\hline $\begin{array}{l}\text { Sport, unstructured } \\
\text { Other leisure }\end{array}$ & Running, fitness \\
\hline Socializing & Social activities with an incidental nature (partying, shopping, chatting) \\
\hline \multicolumn{2}{|l|}{ Media } \\
\hline News & E.g., watching the news, reading a newspaper \\
\hline \multicolumn{2}{|l|}{$\begin{array}{l}\text { Watching TV/Netflix series/- } \\
\text { programs/films }\end{array}$} \\
\hline \multicolumn{2}{|l|}{ Listening to music } \\
\hline Internet/Google & Looking up information online (consuming) \\
\hline (Online) gaming & PlayStation, online gaming, Wii \\
\hline Social media & YouTube, Instagram, WhatsApp, Pinterest, etc. \\
\hline Maintenance & Daily life task interests \\
\hline Food & E.g., eating/making food \\
\hline $\begin{array}{l}\text { Other (personal care, } \\
\text { transportation) }\end{array}$ & E.g., makeup, hairdresser, cycling, riding the bus \\
\hline \multicolumn{2}{|l|}{ Other } \\
\hline Topical interest & $\begin{array}{l}\text { Interests that refer to a small, specific topic (e.g., burns, cancer) are situational, } \\
\text { and not directly related to any activity but rather to a philosophical or } \\
\text { societal theme or topic (caring about the world, self) }\end{array}$ \\
\hline Technology & $\begin{array}{l}\text { Programming, building websites and computers, or other technological } \\
\text { artifacts }\end{array}$ \\
\hline \multicolumn{2}{|l|}{$\begin{array}{l}\text { Thinking/self-actualization } \\
\text { Weekend job }\end{array}$} \\
\hline Miscellaneous & Interests that could be categorized within the other domains \\
\hline
\end{tabular}


Open Access This article is distributed under the terms of the Creative Commons Attribution 4.0 International License (http://creativecommons.org/licenses/by/4.0/), which permits unrestricted use, distribution, and reproduction in any medium, provided you give appropriate credit to the original author(s) and the source, provide a link to the Creative Commons license, and indicate if changes were made.

\section{References}

Ainley, M. (2012). Students' interest and engagement in classroom activities. In S. L. Christenson et al. (Eds.), Handbook of research on student engagement (pp. 283-302). New York: Springer.

Anderson, A. L. (2013). Adolescent time use, companionship, and the relationship with development. In C. L. Gibson \& M. D. Krohn (Eds.), Handbook of life-course criminology (pp. 111-127). New York: Springer.

Akkerman, S. F., \& Bakker, A. (2011). Boundary crossing and boundary objects. Review of Educational Research, 81(2), 132-169. https://doi.org/10.3102/0034654311404435.

Akkerman, S. F., \& Bakker, A. (2012-2014). Interest in science: development across sites of learning. the Netherlands: ELS Starting Grant, Utrecht University.

Akkerman, S. F., \& Bakker, A. (2018). Multiple Interests in Multiple Contexts: Towards person-based research with experience sampling in students' daily lives. Manuscript in preparation.

Azevedo, F. S. (2011). Lines of practice: a practice-centered theory of interest relationships. Cognition and Instruction, 29(2), 147-184. https://doi.org/10.1080/07370008.2011.556834.

Azevedo, F. S. (2013). The tailored practice of hobbies and its implication for the design of interest-driven learning environments. Journal of the Learning Sciences, 22(3), 462-510. https://doi.org/10.1080 /10508406.2012.730082.

Barron, B. (2006). Interest and self-sustained learning as catalysts of development: a learning ecology perspective. Human Development, 49(4), 193-224. https://doi.org/10.1159/000094368.

Barron, B. (2010). Conceptualizing and tracing learning pathways over time and setting. Learning Research as a Human Science. National Society for the Study of Education Yearbook, 109(1), 113-127.

Bassi, M., \& Delle Fave, A. (2004). Adolescence and the changing context of optimal experience in time: Italy 1986-2000. Journal of Happiness Studies, 5(2), 155-179.

Bergin, D. A. (2016). Social influences on interest. Educational Psychologist, 51(1), 7-22. https://doi. org/10.1080/00461520.2015.1133306.

Braund, M., \& Reiss, M. (2006). Towards a more authentic science curriculum: the contribution of out-of-school learning. International Journal of Science Education, 28(12), 1373-1388. https://doi.org/10.1080 /09500690500498419.

Bronfenbrenner, U., \& Morris, P. A. (1998). The ecology of developmental processes. In W. Damon \& R. M. Lerner (Eds.), Handbook of child psychology: theoretical models of human development (pp. 993-1028). Hoboken: Wiley.

Bronkhorst, L. H., \& Akkerman, S. F. (2016). At the boundary of school: continuity and discontinuity in learning across contexts. Educational Research Review, 19, 18-35. https://doi.org/10.1016/j.edurev.2016.04.001.

Cicchetti, D. V. (1994). Guidelines, criteria, and rules of thumb for evaluating normed and standardized assessment instruments in psychology. Psychological Assessment, 6(4), 284.

Coatsworth, J. D., Sharp, E. H., Palen, L. A., Darling, N., Cumsille, P., \& Marta, E. (2005). Exploring adolescent self-defining leisure activities and identity experiences across three countries. International Journal of Behavioral Development, 29(5), 361-370. https://doi.org/10.1080/01650250500166972.

Crone, E. A., \& Dahl, R. E. (2012). Understanding adolescence as a period of social-affective engagement and goal flexibility. Nature Reviews Neuroscience, 13(9), 636-650. https://doi.org/10.1038/nrn3313.

Crowley, K., \& Jacobs, M. (2002). Islands of expertise and the development of family scientific literacy. In G. Leinhardt, K. Crowley, \& K. Knutson (Eds.), Learning conversations in museums (pp. 333-356). Mahwah: Erlbaum.

Crowley, K., Barron, B., Knutson, K., \& Martin, C. K. (2015). Interest and the development of pathways to science. In K. A. Renninger, M. Nieswandt, \& S. Hidi (Eds.), Interest in mathematics and science learning (pp. 297-313). Washington: American Educational Research Association.

Csikszentmihalyi, M., \& Larson, R. (2014). Validity and reliability of the experience sampling method. In M. Csikszentmihalyi (Ed.), Flow and the foundations of positive psychology (pp. 35-54). Dordrecht: Springer.

Eccles, J. S., Midgley, C., Wigfield, A., Buchanan, C. M., Reuman, D., Flanagan, C., \& Mac Iver, D. (1993). Development during adolescence: the impact of stage-environment fit on young adolescents' 
experiences in schools and in families. American Psychologist, 48(2), 90-101. https://doi. org/10.1037/0003-066X.48.2.90.

Falk, J. H., Dierking, L. D., Staus, N. L., Wyld, J. N., Bailey, D. L., \& Penuel, W. R. (2016). The synergies research-practice partnership project: a 2020 vision case study. Cultural Studies of Science Education, 11(1), 195-212. https://doi.org/10.1007/s11422-015-9716-2.

Fisher, K. W., \& Shogren, K. A. (2016). The influence of academic tracking on adolescent social networks. Remedial and Special Education, 37(2), 89-100. https://doi.org/10.1177/0741932515616758.

Grossen, M., Zittoun, T., \& Ros, J. (2012). Boundary crossing events and potential appropriation space in philosophy, literature and general knowledge. In E. Hjörne, G. van der Aalsvoort, \& G. de Abreu (Eds.), Learning, social interaction and diversity-exploring school practices (pp. 15-33). Rotterdam: Sense Publishers.

Gutiérrez, K. D., Baquedano-López, P., \& Tejeda, C. (1999). Rethinking diversity: hybridity and hybrid language practices in the third space. Mind, Culture, and Activity, 6(4), 286-303. https://doi.org/10.1080 $/ 10749039909524733$.

Hamaker, E. L., \& Wichers, M. (2017). No time like the present: discovering the hidden dynamics in intensive longitudinal data. Current Directions in Psychological Science, 26(1), 10-15. https://doi.org/10.1177 /0963721416666518.

Hedegaard, M. (2014). The significance of demands and motives across practices in children's learning and development: an analysis of learning in home and school. Learning, Culture and Social Interaction. https://doi.org/10.1016/j.lcsi.2014.02.008.

Hektner, J. M., Schmidt, J. A., \& Csikszentmihalyi, M. (2007). Experience sampling method: measuring the quality of everyday life. Thousand Oaks: Sage.

Hidi, S., \& Harackiewicz, J. M. (2000). Motivating the academically unmotivated: a critical issue for the $21 \mathrm{st}$ century. Review of Educational Research, 70(2), 151-179.

Hidi, S., \& Renninger, K. A. (2006). The four-phase model of interest development. Educational Psychologist, 41(2), 111-127. https://doi.org/10.1207/s15326985ep4102_4.

Hofer, M. (2010). Adolescents' development of individual interests: a product of multiple goal regulation? Educational Psychologist, 45(3), 149-166. https://doi.org/10.1080/00461520.2010.493469.

Hviid, P. (2016). Borders in education and living - a case of trench warfare. Integrative Psychological and Behavioral Science, 50(1), 44-61. https://doi.org/10.1007/s12124-015-9319-1.

Jacobs, J. E., \& Eccles, J. S. (2000). Parents, task values, and real-life achievement-related choices. In C. Sansone \& J. M. Harackiewicz (Eds.), Intrinsic motivation (pp. 405-439). San Diego: Academy Press.

Kleiber, D., Larson, R., \& Csikszentmihalyi, M. (2014). The experience of leisure in adolescence. In M. Csikszentmihalyi (Ed.), Flow and the foundations of positive psychology (pp. 467-474). Dordrecht: Springer.

Knogler, M., Harackiewicz, J. M., Gegenfurtner, A., \& Lewalter, D. (2015). How situational is situational interest? Investigating the longitudinal structure of situational interest. Contemporary Educational Psychology, 43, 39-50. https://doi.org/10.1016/j.cedpsych.2015.08.004.

Krapp, A. (1999). Interest, motivation and learning: an educational-psychological perspective. European Journal of Psychology of Education, 14(1), 23-40.

Krapp, A. (2002). Structural and dynamic aspects of interest development: theoretical considerations from an ontogenetic perspective. Learning and Instruction, 12(4), 383-409.

Krapp, A., \& Prenzel, M. (2011). Research on interest in science: theories, methods, and findings. International Journal of Science Education, 33(1), 27-50. https://doi.org/10.1080/09500693.2010.518645.

Larson, R. W. (2000). Toward a psychology of positive youth development. American Psychologist, 55(1), 170.

Larson, R. W., \& Verma, S. (1999). How children and adolescents spend time across the world: work, play, and developmental opportunities. Psychological Bulletin, 125(6), 701.

Levey, H. (2010). Trophies, triumphs, and tears: children's experiences with competitive activities. In H. B. Johnson (Ed.), Children and youth speak for themselves: sociological studies of children and youth (Vol. 13, pp. 319-349). Bingley: Emerald Group.

Low, K. D., \& Rounds, J. (2007). Interest change and continuity from early adolescence to middle adulthood. International Journal for Educational and Vocational Guidance, 7(1), 23-36. https://doi.org/10.1007 /s10775-006-9110-4.

Low, K. D., Yoon, M., Roberts, B. W., \& Rounds, J. (2005). The stability of vocational interests from early adolescence to middle adulthood: a quantitative review of longitudinal studies. Psychological Bulletin, 131(5), 713. https://doi.org/10.1037/0033-2909.131.5.713.

Mitchell, M. (1993). Situational interest: its multifaceted structure in the secondary school mathematics classroom. Journal of Educational Psychology, 85(3), 424.

Moeller, J., Dietrich, J., Eccles, J. S., \& Schneider, B. (2016). Passionate experiences in adolescence: situational variability and long-term stability. Journal of Research on Adolescence, 1-18. https://doi.org/10.1111/jora.12297. 
Phelan, P., Davidson, A. L., \& Cao, H. T. (1991). Students' multiple worlds: negotiating the boundaries of family, peer, and school cultures. Anthropology \& Education Quarterly, 22(3), 224-250.

Potvin, P., \& Hasni, A. (2014). Analysis of the decline in interest towards school science and technology from grades 5 through 11. Journal of Science Education and Technology, 23(6), 784-802. https://doi.org/10.1080 /03057267.2014.881626.

Pressick-Kilborn, K., Sainsbury, E., \& Walker, R. (2005). Making sense of theoretical frameworks and methodological approaches: exploring conceptual change and interest in learning from a sociocultural perspective. The Australian Educational Researcher, 32(2), 25-47.

Raudenbush, S. W., Bryk, A. S., \& Congdon, R. (2011). HLM 7.00 for Windows [computer software]. Lincolnwood: Scientific Software International, Inc..

Renninger, K. A., \& Hidi, S. (2011). Revisiting the conceptualization, measurement, and generation of interest. Educational Psychologist, 46(3), 168-184.

Renninger, K. A., \& Hidi, S. (2016). The power of interest for motivation and engagement. New York: Routledge.

Rounds, J., \& Su, R. (2014). The nature and power of interests. Current Directions in Psychological Science, 23(2), 98-103.

Schiefele, U., Krapp, A., \& Winteler, A. (1992). Interest as a predictor of academic achievement: a meta-analysis of research. In K. A. Renninger, S. Hidi, \& A. Krapp (Eds.), The role of interest in learning and development (pp. 183-212). Hillsdale: Lawrence Erlbaum.

Sharp, E. H., \& Coatsworth, J. D. (2012). Adolescent future orientation: the role of identity discovery in selfdefining activities and context in two rural samples. Identity, 12(2), 129-156. https://doi.org/10.1080 $/ 15283488.2012 .668731$.

Smetana, J. G., Campione-Barr, N., \& Metzger, A. (2006). Adolescent development in interpersonal and societal contexts. Annual Review of Psychology, 57, 255-284. https://doi.org/10.1146/annurev. psych.57.102904.190124.

Steinberg, L., \& Morris, A. S. (2001). Adolescent development. Annual Review of Psychology, 52(1), 83-110.

Torquati, J. C., \& Raffaelli, M. (2004). Daily experiences of emotions and social contexts of securely and insecurely attached young adults. Journal of Adolescent Research, 19(6), 740-758. https://doi.org/10.1177 $/ 0743558403260023$.

Tsai, Y. M., Kunter, M., Lüdtke, O., Trautwein, U., \& Ryan, R. M. (2008). What makes lessons interesting? The role of situational and individual factors in three school subjects. Journal of Educational Psychology, 100(2), 460. https://doi.org/10.1037/0022-0663.100.2.460.

Uitto, A., Juuti, K., Lavonen, J., \& Meisalo, V. (2006). Students' interest in biology and their out-of-school experiences. Journal of Biological Education, 40(3), 124-129. https://doi.org/10.1080 /00219266.2006.9656029.

Valsiner, J., \& Van der Veer, R. (2000). The social mind: construction of the idea. Cambridge: Cambridge University Press.

Van den Beemt, A., Akkerman, S., \& Simons, R. J. (2010). The use of interactive media among today's youth: results of a survey. Computers in Human Behavior, 26(5), 1158-1165. https://doi.org/10.1016/j. chb.2010.03.022.

Wenger, E. (2010). Communities of practice and social learning systems: the career of a concept. In C. Blackmore (Ed.), Social learning systems and communities of practice (pp. 179-198). London: Springer.

Zittoun, T. (2015). Social relations and the use of symbolic resources in learning and development. In Social relations in human and societal development (pp. 134-145). Palgrave Macmillan, London.

Zittoun, T., \& Gillespie, A. (2015). Integrating experiences: body and mind moving between contexts. In B. Wagoner, N. Chaudhary, \& P. Hviid (Eds.), Integrating experiences: body and mind moving between contexts (pp. 3-49). Charlotte: Information Age Publishing, Inc..

Esther Slot. Graduate School of Teaching, Leiden University, Willem Einthoven Building, Kolffpad 1, 2333 AL, Leiden, Netherlands. E-mail: e.m.slot@iclon.leidenuniv.nl

Current themes of research:

Interest experience and development in and across contexts in adolescence.

Most relevant publications in the field of Psychology of Education:

Slot, E. M., van Viersen, S., de Bree, E. H., \& Kroesbergen, E. H. (2016). Shared and unique risk factors underlying mathematical disability and reading and spelling disability. Frontiers in Psychology, 7. 